Supporting information. Change of anthocyanin profile after (1) two hours and (2) two weeks of incubation with native sugar beet pectin (SBP), enzyme modified pectin (EMP), or ultrasound modified pectin (UMP) compared to a pectin-free control (Figure S1). UMP was modified for $40 \mathrm{~min}$ and 150 min by ultrasound treatment. EMP was modified by enzyme preparation Rohapect®MaPlus and Klerzym ${ }^{\circledR} 150$ for $1 \mathrm{~h}, 2 \mathrm{~h}$ and $4 \mathrm{~h}$. A: mixture A including cyanidin- $O$-glycosides; B: mixture B including anthocyanin- $O$-glucosides. Different letters indicate significant differences between the treatments; $\mathrm{n}=3$. No significant differences occurred for EMP (1A and 1B).
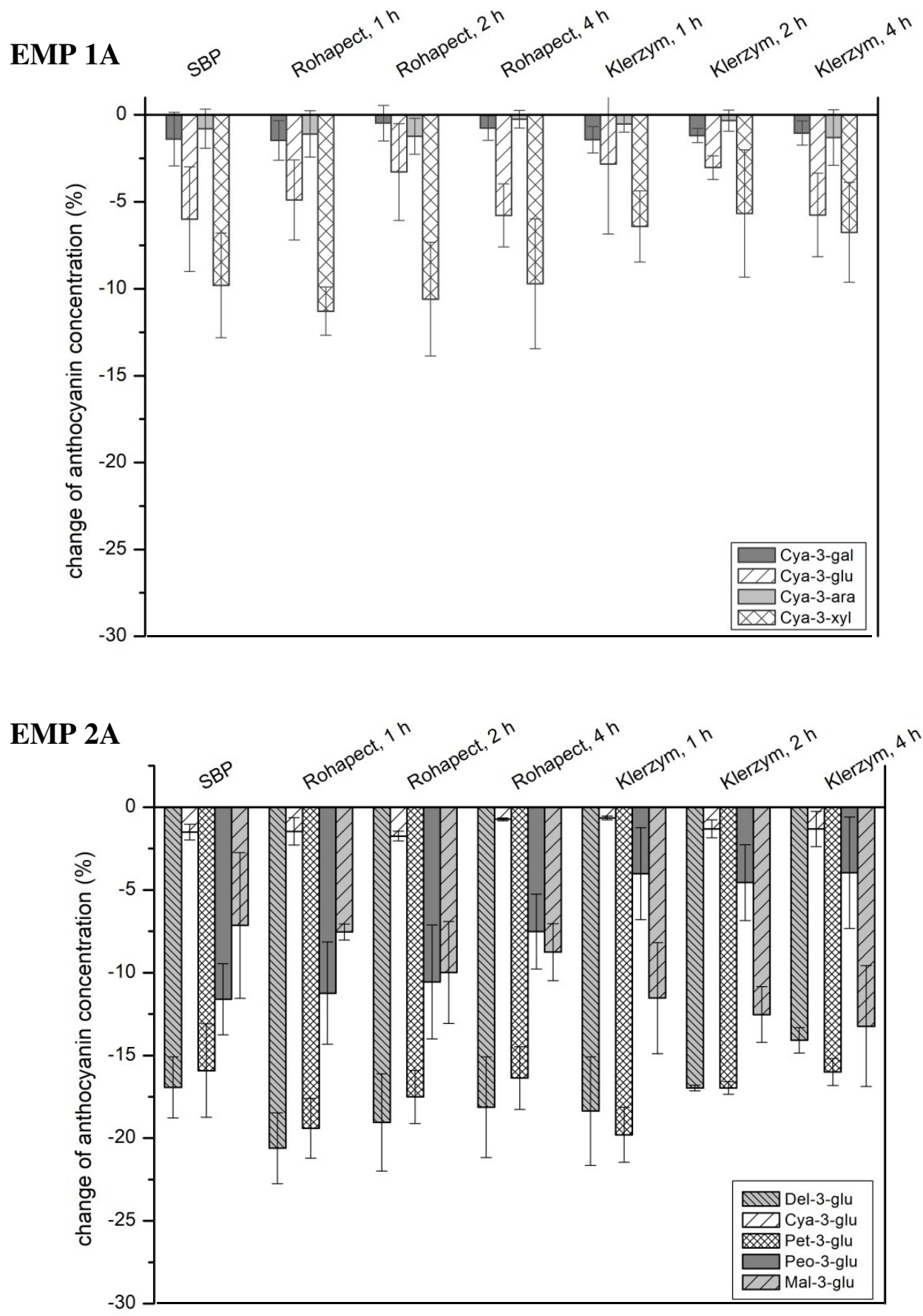


\section{EMP 1B}

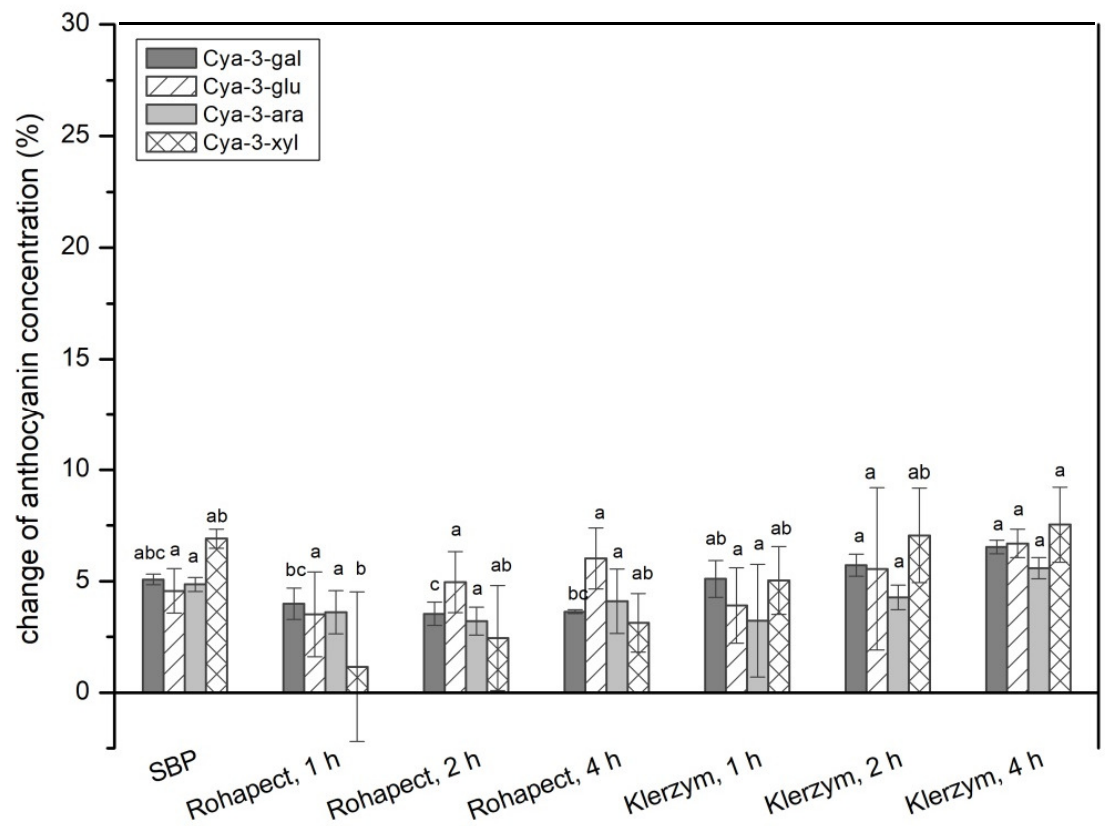

\section{EMP 2B}

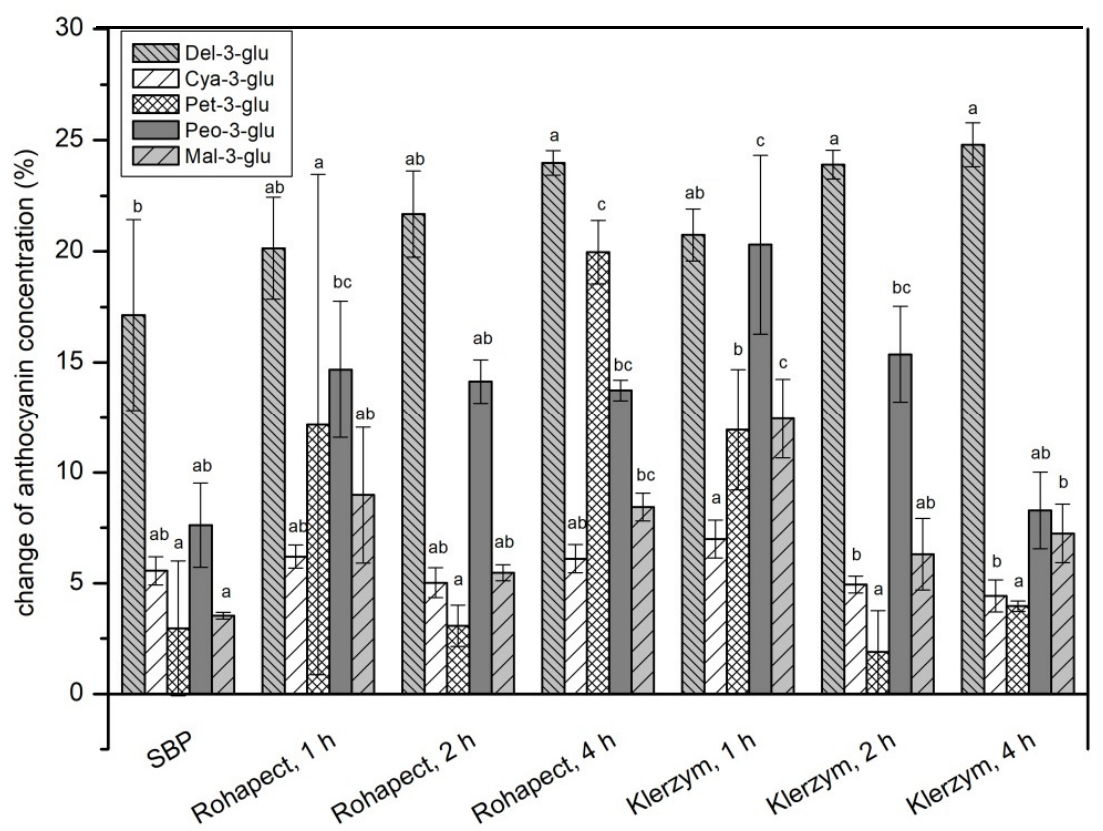



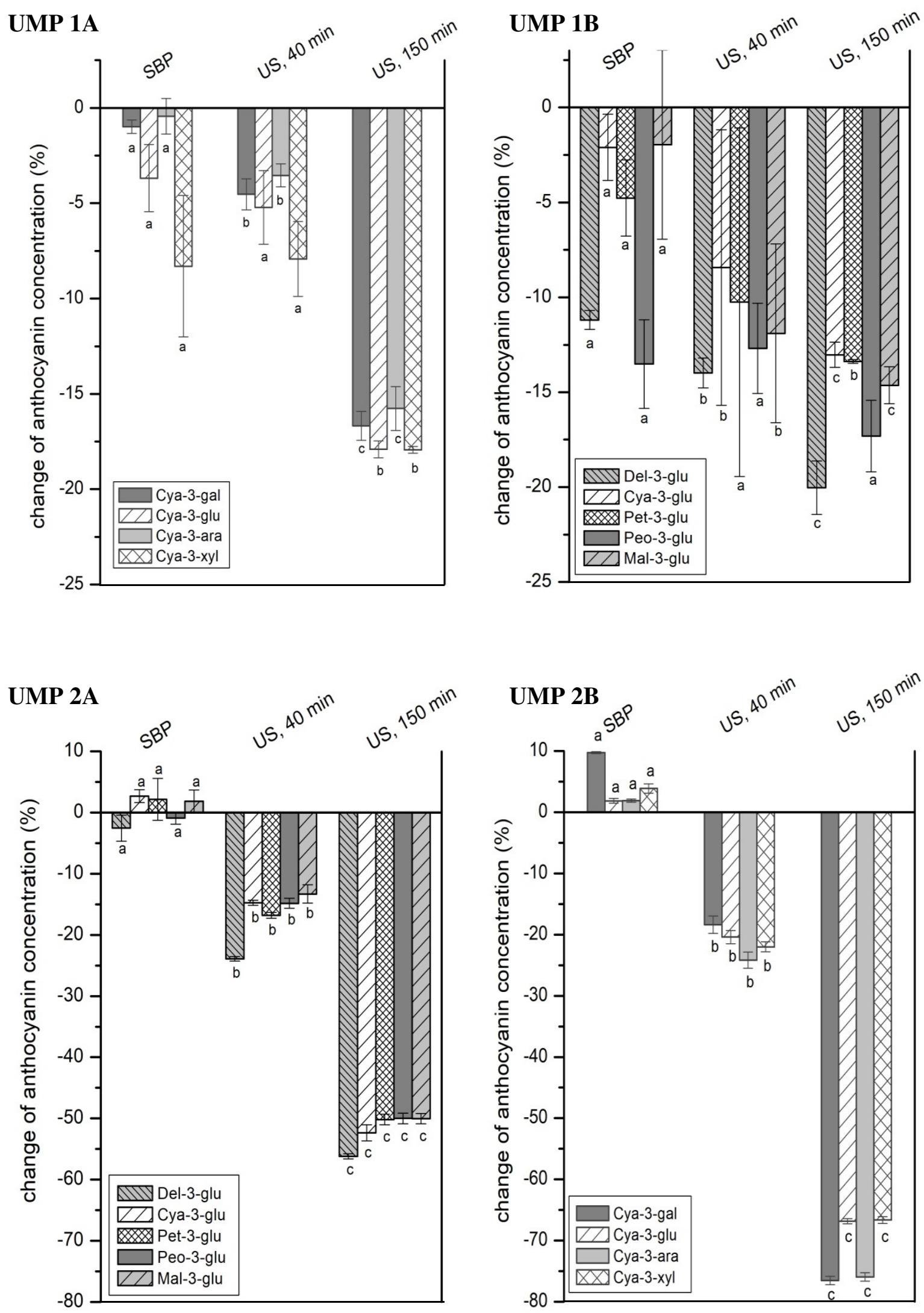